\title{
Randomized Controlled Trial
}

\section{Effectiveness of Repetitive Transcranial Magnetic Stimulation in Patients With Failed Back Surgery Syndrome: A Double-Blind Randomized Placebo- Controlled Study}

Canan Bursali, MD', Feyza Unlu Ozkan, MD², Meryem Yilmaz Kaysin, MD², Nimet Dortcan, $\mathrm{MD}^{3}$, Ilknur Aktas, $\mathrm{MD}^{2}$, and Duygu Geler Kulcu, MD ${ }^{4}$

From: ${ }^{1}$ Aksaray University Training and Research Hospital, Istanbul, Turkey; ${ }^{2}$ Saglik Bilimleri University İstanbul Fatih Sultan Mehmet Training and Research Hospital, Istanbul, Turkey; ${ }^{3}$ stanbul Bilgi University Faculty of Health Sciences, Istanbul, Turkey; ${ }^{4}$ Saglik Bilimleri University Haydarpasa Numune Training and Research Hospital, Istanbul, Turkey

Address Correspondence: Meryem Yilmaz Kaysin, MD Department of Physical Medicine

and Rehabilitation, Saglik

Bilimleri University İstanbul, Fatih Sultan Mehmet Eğitim ve Araştırma Hastanesi

Fiziksel Tıp ve Rehabilitasyon Kliniği H blok

Ataşehir, İstanbul, Turkey E-mail:

drmeryem84@hotmail.com

Disclaimer: There was no external funding in the preparation of this manuscript.

Conflict of interest: Each author certifies that he or she, or a member of his or her immediate

family, has no commercial association (i.e., consultancies, stock ownership, equity interest, patent/licensing arrangements, etc.) that might pose a conflict of interest in connection with the submitted manuscript.

Manuscript received: 03-07-2020 Revised manuscript received: 05-23-2020

Accepted for publication: 06-02-2020

Free full manuscript: www.painphysicianjournal.com
Background: Failed back surgery syndrome (FBSS) is the term of persistent back and/or leg pain after lumbar surgery. Repetitive transcranial magnetic stimulation (r-TMS) is a technique that allows noninvasive and relatively painless stimulation of cerebral cortex. It can reduce the experience of chronic pain by producing the small electrical currents in the cortex via magnetic field.

Objectives: The aim of this study is to determine the effectiveness of $r$-TMS treatment on patients with FBSS.

Study Design: A double-blind, randomized, placebo-controlled trial.

Setting: The Physical Medicine and Rehabilitation Clinic of Istanbul Fatih Sultan Mehmet Training and Research Hospital, Istanbul, Turkey.

Methods: In this double-blinded, randomized, placebo-controlled trial, 20 patients (aged 3465 years) clinically diagnosed as FBSS who had a history of surgery for lumbar disc herniation with persistent back and leg pain were reviewed. Only patients with no root compression and/ or spinal stenosis in postoperative magnetic resonance imaging of lumbar spine were included. Patients were randomly assigned to r-TMS (n:10) and sham (n:10) groups. Patients in the r-TMS group received $5 \mathrm{~Hz}$ of $\mathrm{r}$-TMS as a 20-minute (1,000 pulses) daily session, 5 days per week, for a total of 10 sessions. r-TMS was applied with MagVenture device (MagPro X100, Denmark, 2009) and figure 8 coil (MMC 140 parabolic, MagVenture). Control group received sham r-TMS with the same protocol. Each patient was evaluated at baseline, days 5 and 10 of treatment, and 1 and 3 months after treatment. Visual Analog Scale (VAS), DN4 (Douleur Neuropathique en 4 Questions), Oswestry Disability Index (ODI), Beck Depression Inventory (BDI), and the Pittsburgh Sleep Quality Index (PSQI) were used for evaluation.

Results: There were no statistically significant differences between the groups for age, gender, number of surgeries, pain duration, working status, and drug usage. Significant improvements were achieved in DN4, ODI, BDI, and PSQI scores in the r-TMS group in comparison to the sham group. Both groups displayed improvements in VAS scores, whereas improvement in the sham group was limited to the first month. Achieved improvements in the r-TMS group in terms of VAS, DN4, ODI, BDI, and PSQI scores were sustained at the third month.

Limitations: The limited number of patients and the short follow-up periods are the main limitations of our study. Further placebo-controlled studies with longer follow-up periods and greater number of cases would be beneficial for examining $r$-TMS application as a new treatment option in patients with FBSS.

Conclusions: r-TMS might be an effective alternative treatment in patients with FBSS, further studies with larger groups are needed.

Key words: Back pain, repetitive transcranial magnetic stimulation, failed back surgery syndrome, chronic back pain

Pain Physician 2021: 24:E23-E30 
ow back pain (LBP) is an important health problem that causes significant labor and economic losses in young adults and negatively affects their quality of life. The lifetime prevalence of LBP is $70 \%$ to $85 \%$ (1). Failed back surgery syndrome (FBSS) is a general description of the continuation or recurrence of low back and/or leg pain after primary lumbar surgery. In other words, FBSS is the failure to meet the surgeon's and patient's preoperative expectations. The success rate in low back surgery is variable; failure has been reported in $20 \%$ to $40 \%$ cases (2). Despite successful disc surgery, a number of patients with FBSS still experience chronic back and leg pain.

Chronic LBP is poorly understood in FBSS. In many cases, the causes of pain disappear, but the nervous system lesion or disease continues to sustain the pain (3). Both peripheral and central mechanisms play a role in LBP chronicity. If the peripheral nociceptive signal cannot be prevented, chronic stimulation of the receptors at the postsynaptic membrane causes plastic changes, such as the appearance of new receptors, and the neuropathic pain component may become dominant (4). Subsequently, the postsynaptic nerve ends are spontaneously activated and continue to send signals perceived as pain to pain centers, even if the peripheral signal is stopped, leading to central sensitization $(5,6)$.

Repetitive transcranial magnetic stimulation ( $r-$ TMS) is a noninvasive, well-tolerated treatment that can stimulate cortical neurons by electromagnetic stimulation. The procedure is based on the creation of a magnetic field in the targeted cortical area of the patient with the help of a coil. It is a promising technique in the treatment of depression, complex regional pain syndrome, diabetic polyneuropathy, post-stroke pain, neuropathic pain, and fibromyalgia due to its ability to alter brain functions by increasing cortical plasticity (7). The use of r-TMS for neuropathic pain has also been reported to reduce pain scores by greater than $30 \%(8,9)$.

Therefore the current study sought to determine if r-TMS can be used as an alternative treatment option for FBSS because of its noninvasive and comfortable tolerability in patients with FBSS who have difficulties in treatment. The aim of this study was to investigate the efficacy of r-TMS treatment on neuropathic pain and functionality in patients with FBSS.

\section{Methods}

A randomized, prospective, double-blind, placebocontrolled study was conducted at the Physical Medicine and Rehabilitation Clinic of Istanbul Fatih Sultan
Mehmet Training and Research Hospital in patients aged between 18 and 65 years who had FBSS. Twenty patients with no neurologic deficits and persistent back and leg pain at least 6 months post-lumbar surgeries were included in the study. Each patient was evaluated at baseline, days 5 and 10 of treatment, and 1 and 3 months after the treatment. Age, gender, occupation, number of lumbar operations, duration of symptoms, medications used for pain, and previous treatments for pain were recorded. Additionally, a detailed history of systemic diseases was obtained. All patients underwent a general posture evaluation and lumbar examination (inspection, palpation, and range of motion of the lumbar joint) and a neurologic examination evaluating muscle strength, sensory perception, standard reflexes, and pathological reflexes. Lumbar magnetic resonance imaging (MRI) results after the last low back surgery in all patients were analyzed. Exclusion criteria included the following: history of epilepsy, cerebrovascular disease, head trauma, brain surgery, implanted cardiac pacemaker, or physical therapy for the lumbar region within the last 6 months. Patients who had concrete evidence of root compression and/or serious spinal stenosis detected in lumbar MRI, neurologic deficit on physical examination, and/or current/planned pregnancy were also excluded. Nerve root compression was defined as the pressure of nerve roots in neural foramina by disc and/or osteophytes, and all MRIs were evaluated by an experienced radiologist in musculoskeletal radiology. Written informed consent was obtained from all patients. All procedures were conducted in accordance with the Declaration of Helsinki of 1975 and approved by the local institutional clinical research ethical committee (2014/10). The study is registered at Clinical Trial. gov with unique ID: NTC04003714, and the CONSORT standard for clinical trial reporting was implemented.

\section{Study Intervention and Procedure}

Central motor conduction time, motor unit potential latency, motor unit potential amplitude, and resting threshold were calculated from the abductor pollicis brevis muscles while the patients were in a supine and relaxed position prior to treatment.

In the first group, the primary motor field was targeted with $70 \%$ excitation intensity of resting threshold, and r-TMS was applied for 5 sessions at $5-\mathrm{Hz}$ of r-TMS was applied as a 20 -minutes (1,000 pulses) daily sessions, 5 days per week, for a total of 10 sessions. $r$ TMS treatment was performed with a MagVenture device (MagPro X100, Tonica Electronic, Farum, Denmark) 
and an 8-shaped parabolic coil (MMC 140 parabolic, MagVenture, Tonica Electronic, Farum, Denmark). The patients in the second group were positioned in the same manner as the patients in the first group, but the device was not in operation. The sham treatment was performed by playing a sound recording during the application. Patients in both groups were informed about FBSS, general waist protection principles, and lumbar isometric exercises.

\section{Outcome Evaluation}

Patient evaluation was performed at baseline, days 5 and 10 of treatment, and 1 and 3 months after treatment. All patients were evaluated by the same physiatrist (CB) who was blinded to the randomization process and treatment protocols. All groups were evaluated for low back and leg pain using the Visual Analog Scale (VAS) for rest, activity, and sleep disturbance. Patients were instructed to indicate the severity of pain on a 10 -point scale $(0=$ no pain, $5=$ moderate pain, and $10=$ intolerable pain) (10). Functional status in all groups was evaluated with the Oswestry Disability Index (ODI). The ODI consists of 10 topics concerning pain; lifting; self-care ability; ability to walk, sit, stand, and travel; social life; and sleep quality. The ODI is intended to assess disability and quality of life associated with LBP, and scores range from 0 (no disability) to 100 (maximum disability possible) $(11,12)$. The DN4 (Douleur Neuropathique en 4 Questions) interview questionnaire was used to differentiate neuropathic pain from nonneuropathic pain $(13,14)$. The questionnaire consists of 10 items, the first 7 items are related to pain characteristics and sensations and the remaining items are related to examination. For each item, a score of " 1 " is given if the answer is "yes" and a score of " 0 " is given if it is "no." The patient is defined to have neuropathic pain if the sum of all 10 items is calculated to be 4 or more. The Pittsburgh Sleep Quality Index (PSQI) was used to evaluate sleep quality $(15,16)$. PSQI is a self-rated questionnaire that assesses sleep quality and sleep disturbances over a 1-month time interval. In scoring the PSQI, 7 component scores are derived, each scored 0 (no difficulty) to 3 (severe difficulty), and the component scores are summed to produce a global score (range, 0-21). Symptoms of depression were evaluated using the Beck Depression Inventory (BDI) $(17,18)$. BDI assesses both the presence and the severity of depressive symptoms. It has 21 items describing symptoms of depression. Each item is scored on a 4-point scale ranging from 0 (absent) to 3 (severe) with a total summed score range 0 to 63 . Higher scores indicate more severe depressive symptoms.

\section{Randomization}

All evaluations (initial, inclusion criteria, pre- and post-treatment) were performed by the investigating physician (CB). Randomization was performed by a coin flip by a person extraneous to the study. All r-TMS and sham r-TMS were performed by another investigating physician (MYK).

\section{Statistical Analysis}

Number Cruncher Statistical System (NCSS, Utah, USA) 2007, Power Analysis and Sample Size (PASS, Utah, USA) 2008, and IBM Statistics 22 (IBM SPSS, Istanbul, Turkey) were used for statistical analysis. The Student t-test was used in evaluating the study data for comparing statistical methods (average, standard deviation, median, frequency, and ratio) alongside quantitative data and parameters that show normal distribution. The Mann-Whitney $U$ test was used in the comparison of 2 groups that did not show normal distribution. Paired sample t-test was used for intragroup comparisons of normally distributed parameters, and the Wilcoxon sign test was used for intragroup comparisons of nonnormal distribution parameters. The $\chi^{2}$ test and Fisher exact $\chi^{2}$ were used for the comparison of qualitative data. Significance was evaluated at a $P$ value of $<0.05$.

\section{RESULTS}

Forty-two patients were assessed for eligibility, 9 patients declined to participate, 10 patients did not meet the inclusion criteria. Twenty-three patients were allocated to 2 groups as r-TMS treatment and sham groups. Two patients were dropped out because they were not compatible to the assessments ( $r$-TMS group), and one patient discontinued the treatment (sham group). Only one patient in the r-TMS group suffered from mild headache after the first $r$-TMS session, which recovered spontaneously. No other systemic or local side effects were reported in any of the groups during or at the end of the treatment. Ten patients in each group remained for analysis (Fig. 1).

No significant differences were found between the $r$-TMS and sham groups for age, gender, body mass index, number of operations, time period after operation, symptom duration, work status, or drug usage $(P$ $>0.05)$. Table 1 demonstrates the demographic parameters and disease-related variables. There were no 


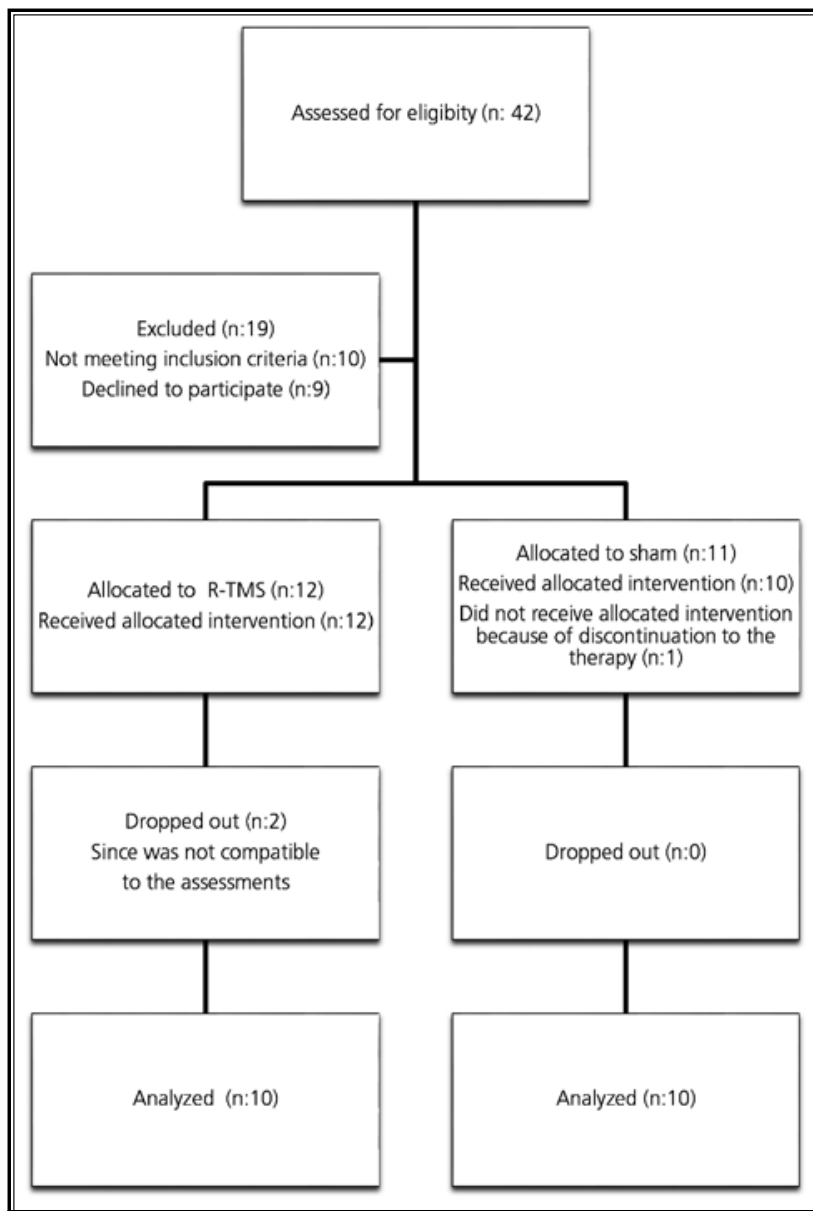

Fig 1. Flow chart of patients through the study.
Table 1. Demographic parameters and disease-related variables.

\begin{tabular}{|c|c|c|c|}
\hline & Pr-TMS & Sham & $\overline{P P}$ \\
\hline Age, med \pm SD & $48.20 \pm 9.53$ & $54.40 \pm 10.04$ & 0.174 \\
\hline $\mathrm{BMI}, \mathrm{med} \pm \mathrm{SD}$ & $26.9 \pm 3.39$ & $28.89 \pm 3.99$ & 0.245 \\
\hline $\begin{array}{l}\text { Number of operations, } \\
\text { med } \pm \text { SD (median) }\end{array}$ & $\begin{array}{c}1.7 \pm 0.82 \\
\quad(1.5)\end{array}$ & $1.4 \pm 0.52(1)$ & 0.445 \\
\hline $\begin{array}{l}\text { Time period after } \\
\text { operation, med } \pm \text { SD } \\
\text { (median) }\end{array}$ & $3.3 \pm 2.0(3)$ & $6.7 \pm 6.57(4)$ & 0.379 \\
\hline \multicolumn{4}{|l|}{ Gender, n (\%) } \\
\hline Female & $7(70 \%)$ & $7(70 \%)$ & \multirow{2}{*}{1,000} \\
\hline Male & $3(30 \%)$ & $3(30 \%)$ & \\
\hline \multicolumn{4}{|c|}{ Symptom duration (year), n (\%) } \\
\hline$<1$ year & $1(10 \%)$ & $0(0 \%)$ & \multirow{4}{*}{0.212} \\
\hline $1-4$ years & $6(60 \%)$ & $3(30 \%)$ & \\
\hline 5-10 years & $0(0 \%)$ & $2(20 \%)$ & \\
\hline$>10$ years & $3(30 \%)$ & $5(50 \%)$ & \\
\hline \multicolumn{4}{|l|}{ Work, n (\%) } \\
\hline Housewife & $6(60 \%)$ & $6(60 \%)$ & \multirow{5}{*}{0.649} \\
\hline Retired & $1(10 \%)$ & $2(20 \%)$ & \\
\hline Construction worker & $1(10 \%)$ & $0(0 \%)$ & \\
\hline Employer & $1(10 \%)$ & $1(10 \%)$ & \\
\hline Cleaner & $1(10 \%)$ & $1(10 \%)$ & \\
\hline \multicolumn{4}{|l|}{ Drug use, $n(\%)$} \\
\hline Yes & $6(60 \%)$ & $6(60 \%)$ & \multirow{2}{*}{1,000} \\
\hline No & $4(40 \%)$ & $4(40 \%)$ & \\
\hline
\end{tabular}

BMI, body mass index; med, median; SD, standard deviation. significant differences between VAS, DN4, ODI, PSQI, or BDI scores at baseline evaluation of both groups $(P$ $>0.05$ ). Table 2 demonstrates the comparison of $r$-TMS and sham treatment groups according to VAS scores for rest, activity, and night pain, and Table 3 demonstrates the comparison of $r$-TMS and sham treatment groups according to DN4, ODI, PSQI, and BDI scores.

When $r$-TMS and sham treatment groups were compared according to VAS scores, there was only a significant difference in pain with activity at days 5 and 10 of treatment and at 1 month after treatment $(P<$ 0.05) (Table 2). Activity VAS scores were lower in the r-TMS group than those in the sham group (Table 2). The DN4 scores at day 10 of treatment and 1 month after treatment were higher in the sham group than in the r-TMS group $(P<0.05)$ (Table 3$)$. The ODI scores were higher in the $\mathrm{r}$-TMS group than in the sham group at baseline, and were lower in the r-TMS group than in the sham group at day 10 of treatment $(P<0.05)$ (Table 3). The PSQI scores showed only a significant difference between the $\mathrm{r}$-TMS and sham groups at day 10 of treatment, with lower PSQI scores in the r-TMS group $(P<0.05)$ (Table 3). BDI scores at day 10 of treatment, 1 month after treatment, and 3 months after treatment were significantly lower in the r-TMS group than in the sham group $(P<0.05)$ (Table 3$)$.

\section{Discussion}

Despite all advances in surgical techniques, FBSS occurs in $20 \%$ to $40 \%$ of patients after spinal surgery, resulting in low back pain, leg pain, and functional failure (2). Several mechanisms have been proposed regarding pre- and postoperative neuropathic pain after spinal surgery. In patients with long-term LBP, long-term compression of the nerve roots may cause nociceptive pain to become neuropathic pain $(5,19)$. 
Repetitive Transcranial Magnetic Stimulation Treatment in FBSS

Table 2. Comparison of r-TMS and sham treatment groups according to VAS scores for rest, activity, and night pain.

\begin{tabular}{|c|c|c|c|c|c|c|c|c|c|}
\hline & \multicolumn{3}{|c|}{ Resting VAS } & \multicolumn{3}{|c|}{ Activity VAS } & \multicolumn{3}{|c|}{ Night Pain VAS } \\
\hline & r-TMS & Sham & \multirow[b]{2}{*}{$P$} & r-TMS & Sham & \multirow[b]{2}{*}{$P$} & r-TMS & Sham & \multirow[b]{2}{*}{$P$} \\
\hline & $\begin{array}{c}\operatorname{med} \pm \mathrm{SD} \\
(\operatorname{median})\end{array}$ & $\begin{array}{c}\operatorname{med} \pm \text { SD } \\
(\text { median })\end{array}$ & & $\begin{array}{c}\operatorname{med} \pm \mathrm{SD} \\
(\text { median })\end{array}$ & $\begin{array}{c}\operatorname{med} \pm \mathrm{SD} \\
(\text { median })\end{array}$ & & $\begin{array}{c}\text { med } \pm \text { SD } \\
(\text { median) }\end{array}$ & $\begin{array}{c}\operatorname{med} \pm \mathrm{SD} \\
(\text { median })\end{array}$ & \\
\hline BT & $6.3 \pm 2.83(7)$ & $5.9 \pm 3.6(6.5)$ & 1.000 & $7.5 \pm 1.43(8)$ & $8.2 \pm 1.62(8)$ & 0.335 & $7.5 \pm 2.17(8)$ & $5.7 \pm 4.16(7.5)$ & 0.515 \\
\hline 5th day & $3.3 \pm 1.95(3)$ & $5.0 \pm 3.2(6)$ & 0.135 & $5.2 \pm 1.55(5.5)$ & $7.0 \pm 1.7(7)$ & 0.026 & $3.1 \pm 2.28(2.5)$ & $4.7 \pm 3.53(5)$ & 0.281 \\
\hline 10th day & $2.2 \pm 1.99(2.5)$ & $4.1 \pm 2.77(5)$ & 0.116 & $3.3 \pm 2.06(3)$ & $6.6 \pm 2.72(7.5)$ & 0.016 & $2.0 \pm 1.83(2)$ & $3.8 \pm 3.46(5)$ & 0.260 \\
\hline 1 month AT & $3.3 \pm 2.41$ & $5.3 \pm 3.47(5.5)$ & 0.122 & $4.2 \pm 2.15$ & $7.5 \pm 1.84(7.5)$ & 0.004 & $3.2 \pm 1.69(3.5)$ & $4.5 \pm 3.5(5)$ & 0.228 \\
\hline 3 months AT & $3.3 \pm 2.91(3)$ & $4.7 \pm 3.2(5)$ & 0.284 & $4.6 \pm 2.46(5)$ & $6.9 \pm 2.23(7.5)$ & 0.056 & $3.6 \pm 2.27(3.5)$ & $4.0 \pm 3.37(4)$ & 0.759 \\
\hline BT 5th day & 0.008 & 0.041 & & 0.017 & 0.014 & & 0.005 & 0.059 & \\
\hline BT 10th day & 0.007 & 0.026 & & 0.008 & 0.027 & & 0.007 & 0.041 & \\
\hline BT 1 month AT & 0.018 & 0.083 & & 0.018 & 0.343 & & 0.011 & 0.078 & \\
\hline BT 3 months AT & 0.016 & 0.042 & & 0.018 & 0.041 & & 0.018 & 0.066 & \\
\hline
\end{tabular}

AT, after treatment; BT, before treatment; med, median; SD, standard deviation.

Table 3. Comparison of r-TMS and sham treatment groups according to DN4, ODI, PSQI, and BDI scores.

\begin{tabular}{|c|c|c|c|c|c|c|c|c|c|c|c|c|}
\hline & \multicolumn{3}{|c|}{$\begin{array}{l}\text { Neuropathic Pain (DN4) } \\
\text { Scores }\end{array}$} & \multicolumn{3}{|c|}{ ODI Scores } & \multicolumn{3}{|c|}{ PSQI Scores } & \multicolumn{3}{|c|}{ BDI Scores } \\
\hline & r-TMS & Sham & \multirow[b]{2}{*}{$P$} & r-TMS & Sham & \multirow[b]{2}{*}{$P$} & r-TMS & Sham & \multirow[b]{2}{*}{$P$} & r-TMS & Sham & \multirow[b]{2}{*}{$P$} \\
\hline & $\begin{array}{c}\operatorname{med} \pm \mathrm{SD} \\
(\text { median})\end{array}$ & $\begin{array}{c}\operatorname{med} \pm \mathrm{SD} \\
(\text { median })\end{array}$ & & $\begin{array}{c}\operatorname{med} \pm \mathrm{SD} \\
(\text { median })\end{array}$ & $\begin{array}{c}\operatorname{med} \pm \mathrm{SD} \\
(\text { median})\end{array}$ & & $\begin{array}{c}\operatorname{med} \pm \mathrm{SD} \\
(\text { median })\end{array}$ & $\begin{array}{c}\operatorname{med} \pm \mathrm{SD} \\
(\text { median})\end{array}$ & & $\begin{array}{c}\operatorname{med} \pm \mathrm{SD} \\
(\text { median})\end{array}$ & $\begin{array}{c}\operatorname{med} \pm \mathrm{SD} \\
(\text { median})\end{array}$ & \\
\hline BT & $\begin{array}{l}6.5 \pm 1.65 \\
(6.5)\end{array}$ & $\begin{array}{l}5.4 \pm 1.78 \\
(5)\end{array}$ & 0.166 & $35.0 \pm 3.37$ & $30.1 \pm 6.26$ & 0.043 & $\begin{array}{l}9.5 \pm 4.38 \\
\quad(10)\end{array}$ & $\begin{array}{l}9.3 \pm 6.34 \\
(7.5)\end{array}$ & 0.733 & $\begin{array}{l}20.1 \pm 12.3 \\
\quad(15.5)\end{array}$ & $\begin{array}{l}19.8 \pm 12.19 \\
(17)\end{array}$ & 0.705 \\
\hline 5th day & $\begin{array}{c}3.4 \pm 1.9 \\
(3.5)\end{array}$ & $\begin{array}{c}5.0 \pm 2.62 \\
\quad(5.5)\end{array}$ & 0.169 & $26.1 \pm 5.67$ & $28.6 \pm 5.67$ & 0.366 & $\begin{array}{l}5.1 \pm 2.69 \\
(3.5)\end{array}$ & $\begin{array}{l}8.8 \pm 6.6 \\
(7)\end{array}$ & 0.191 & $\begin{array}{c}11.6 \pm 11.03 \\
(8)\end{array}$ & $\begin{array}{c}17.5 \pm 10.22 \\
(15.5)\end{array}$ & 0.058 \\
\hline 10th day & $\begin{array}{l}2.6 \pm 2.01 \\
\quad(2)\end{array}$ & $\begin{array}{l}5.2 \pm 2.7 \\
\quad(5)\end{array}$ & 0.039 & $21.1 \pm 6.4$ & $27.9 \pm 6.9$ & 0.035 & $\begin{array}{l}3.7 \pm 1.7 \\
(3)\end{array}$ & $\begin{array}{l}8.3 \pm 5.54 \\
\quad(6)\end{array}$ & 0.019 & $\begin{array}{l}7.1 \pm 7.11 \\
\quad(5)\end{array}$ & $\begin{array}{l}16.5 \pm 8.56 \\
\quad(16)\end{array}$ & 0.009 \\
\hline $\begin{array}{l}1 \text { month } \\
\text { AT }\end{array}$ & $\begin{array}{l}3.9 \pm 1.91 \\
(4)\end{array}$ & $\begin{array}{l}5.9 \pm 1.66 \\
(6)\end{array}$ & 0.030 & $23.5 \pm 8.09$ & $28.3 \pm 5.95$ & 0.148 & $\begin{array}{l}4.5 \pm 2.42 \\
(3.5)\end{array}$ & $\begin{array}{l}8.7 \pm 7.45 \\
(6)\end{array}$ & 0.195 & $\begin{array}{l}8.4 \pm 5.89 \\
(6.5)\end{array}$ & $\begin{array}{l}18.6 \pm 12.08 \\
\quad(16)\end{array}$ & 0.017 \\
\hline $\begin{array}{l}3 \text { months } \\
\text { AT }\end{array}$ & $\begin{array}{c}4.2 \pm 1.93 \\
(5)\end{array}$ & $\begin{array}{l}6.2 \pm 2.3 \\
(6)\end{array}$ & 0.059 & $23.2 \pm 8.72$ & $28.1 \pm 5.97$ & 0.160 & $\begin{array}{l}5.1 \pm 4.2 \\
\quad(3)\end{array}$ & $\begin{array}{l}8.9 \pm 7.36 \\
(7)\end{array}$ & 0.195 & $\begin{array}{l}9.3 \pm 6.55 \\
(6.5)\end{array}$ & $\begin{array}{l}18.6 \pm 12.0 \\
(16)\end{array}$ & 0.044 \\
\hline BT 5th day & 0.005 & 0.458 & & 0.001 & 0.005 & & 0.008 & 0.500 & & 0.005 & 0.027 & \\
\hline $\begin{array}{l}\text { BT 10th } \\
\text { day }\end{array}$ & 0.005 & 0.680 & & 0.001 & 0.004 & & 0.008 & 0.398 & & 0.005 & 0.066 & \\
\hline $\begin{array}{l}\text { BT } 1 \\
\text { month AT }\end{array}$ & 0.007 & 0.206 & & 0.002 & 0.182 & & 0.011 & 0.776 & & 0.012 & 0.172 & \\
\hline $\begin{array}{l}\text { BT } 3 \\
\text { months AT }\end{array}$ & 0.011 & 0.084 & & 0.003 & 0.138 & & 0.017 & 0.831 & & 0.008 & 0.171 & \\
\hline
\end{tabular}

AT, after treatment; BT, before treatment; med, median; SD, standard deviation.

Neuropathic pain after spinal surgery may occur (1) as a result of iatrogenic injury to the nerves and muscles in the operation area, (2) due to stress in the body, or (3) due to transmission of ectopic impulses from the nerve roots or dorsal root ganglion to the central nervous system (20). The treat- ment approach of neuropathic pain is to alleviate pain and improve quality of life. Tricyclic antidepressants, anticonvulsants, opioids, and topical local anesthetics are currently used in the medical treatment of neuropathic pain; however, these treatment options are not ideal. Neurostimulation therapy 
may be used in cases in which medical treatment does not benefit the patient or is inadequate.

In the treatment of neuropathic pain in FBSS, additional surgical treatment may be indicated in the presence of a structural abnormality (such as stenosis, instability, and recurrent disc herniation) (21). In the absence of structural abnormalities, the success of secondary operation in FBSS is not superior to conservative pain treatment. On the contrary, the probability of surgical success decreases as the number of operations increases (3).

Spinal cord stimulation (SCS), one of the interventional methods for the symptoms, is a recommended treatment in patients with FBSS (3). A study by Kumar et al (22) concluded that SCS is effective in patients with FBSS and neuropathic pain. However, the complications of an invasive procedure (such as dural rupture, spinal root or cord damage, bleeding, infection, and electrode dislocation and migration) limit the application of SCS. Another neurostimulation technique, direct brain stimulation (DBS), has also been shown to be effective in FBSS. A study by Rasche et al (23) found the best long-term DBS treatment results for patients with chronic pain syndrome and patients with FBSS. This study showed for the first time that the mechanisms of the methods applied to the lumbar region (such as SCS, intrathecal opioid applications, and TENS) are generally supraspinal, and therefore pain may be decreased with stimulation applied to the brain in patients with FBSS (23). However, the high cost and complication rate of DBS treatment has limited further studies. Dural motor cortical stimulation (MCS) has shown satisfactory results in the treatment of neuropathic pain as a less invasive technique, but a need for $70 \%$ recurring intervention forced researchers to investigate new treatment options (24). Based on these studies, r-TMS, which provides noninvasive stimulation of the brain and has recently been used in the treatment of multiple diseases, may also be effective in FBSS.

$r$-TMS leads to electrochemical changes in the transmembrane potential by causing an electrical field in the magnetic field and neuronal membranes of the cerebral cortex. Recent studies have focused on the possibility that $r$-TMS is involved in the reorganization of cerebral cortex and other brain regions involved in chronic pain. $r$-TMS is a treatment option in a very large patient group, and the US Food and Drug Administration (FDA) has approved its use as a treatment in resistant depression. r-TMS has also been used for the treatment of neuropathic pain, trigeminal neuralgia, postherpetic neuralgia, complex regional pain syn- drome, post-stroke pain, phantom pain, and chronic $\operatorname{LBP}(7,25,26)$. Considering the literature suggesting that $r$-TMS may be an effective treatment for chronic LBP and central neuropathic pain, we investigated the efficacy of r-TMS in patients with FBSS, who are difficult to treat in clinical practice.

There is no standard protocol for the duration and frequency of $r$-TMS found in the literature. The first study investigating the effect of $r$-TMS on chronic pain was conducted by Lefaucheur et al(27). In this placebocontrolled study, 14 patients with neurogenic pain were included in the active or placebo groups, and a singlesession $10-\mathrm{Hz}$ frequency pulse was applied over the motor cortex for 20 minutes. Pain levels were evaluated by VAS, which were significantly lower in the active group compared with the placebo group (27). Three years later, a study by Lefaucheur et al (28) included a greater number of patients and found a decrease in VAS scores in both groups. However, the decrease in VAS scores in the active group was higher than that in the placebo group (28).

A study by Andrade et al (29) reported that r-TMS provides analgesia by increasing endogenous opioid synthesis. The significant decrease in VAS scores detected in our study may be due to this effect of r-TMS. In the current study, there was a significant decrease of DN4 scores as a measurement of neuropathic pain with r-TMS treatment, but no improvement was observed in the sham group. A study by Denis et al (30) applied rTMS in a patient with refractory cancer pain who scored 7 points on the DN4 questionnaire. They stated that the application significantly reduced pain and improved the quality of life by reducing the dose of the analgesic used; therefore r-TMS may be an effective treatment option in patients with drug-resistant neuropathic pain (30). Additionally, they suggested that the statistically significant improvement in ODI scores in both groups may have been caused by the home exercise program given to patients.

Depression, panic and anxiety disorders, and sleep problems are frequently seen in patients with chronic LBP (5). r-TMS received FDA approval for treatment of depression in 2008, and it has since been used to treat depression resistant to medical therapy in clinical practice with very satisfactory results. A study by Kedzior and Reitz (31) investigated the antidepressant effect of r-TMS in a meta-analysis. They analyzed 40 double-blind, randomized, placebo-controlled trials and concluded that $r$-TMS applied to the dorsolateral prefrontal cortex was moderately effective in the treatment of depression 
(31). Hosomi et al (32) conducted a randomized, placebocontrolled, double-blind crossover study in patients with neuropathic pain; they applied 10 sessions of 5-Hz r-TMS to the primary motor cortex. However, BDI measures did not differ between the treatment and placebo groups (32). In the current study, significant improvements in PSQI and BDI measures in the treatment group showed that $r$-TMS may also be an option in patients with paininduced sleep disorders.

The potential adverse effects of $r$-TMS treatment are headache and scalp discomfort at the side of stimulation (7). In this study, only one patient suffered from mild headache after the first $r$-TMS session and recovered spontaneously. Cardiac pacemaker and metallic objects in or near the head are the major contraindications of r-TMS (9). We preferred to also exclude the history of epilepsy, cerebrovascular disease, head trauma, brain surgery, and current or/ planned pregnancy to minimize the risk of adverse effects and to provide more homogenous study groups.

\section{Limitations}

The limited number of patients and the short follow-up periods are the main limitations of our study. Further placebo-controlled studies with longer follow-up periods and greater number of cases would be beneficial for examining r-TMS application as a new treatment option in patients with FBSS.

\section{Conclusions}

In this study, we investigated the neurostimulation technique of $r$-TMS therapy as an alternative treatment option in patients with FBSS, as it is noninvasive, more tolerable, and more comfortable compared with SCS, DBS, and MCS. In a study by Saitoh et al (33) most significant improvement in pain score was achieved after stimulating the primary motor cortex of the brain, postcentral gyrus, supplementary motor area, and premotor area with r-TMS (33). Although primary motor field stimulation is used in the majority of studies, it is still unclear why stimulation of this region leads to pain reduction. The current hypothesis is that the primary motor field stimulation also activates other parts of the brain and is thus the most effective site for pain relief.

Cortical fibers terminate in the spinal cord laminae and synapse with inhibitory intermediate neurons in the spinal cord. Thus, in addition to direct stimulation of the primary motor cortex, r-TMS is also predicted to cause neurochemical changes in cells in the spinal cord (34). In the current study, the improvement in pain, neuropathic pain, functionality, sleep parameters, and depression parameters in patients with FBSS undergoing r-TMS treatment may be explained by this mechanism.

\section{REFERENCES}

1. Nijs J, Apeldoorn A, Hallegraeff $\mathrm{H}$, et al. Low back pain: Guidelines for the clinical classification of predominant neuropathic, nociceptive, or central sensitization pain. Pain Physician 2015; 18:333-346.

2. Baber Z, Erdek MA. Failed back surgery syndrome: current perspectives. J Pain Res 2016; 9:979-987.

3. Clark JR, Nijs J, Smart K, Holmes P, Yeowell G, Goodwin PC. Prevalence of extreme trait sensory profiles and personality types in nonspecific chronic low back pain with predominant central sensitization: Secondary analysis of an international observational study. Pain Physician 2019; 22(3):E181-E19o.

4. Audette JF, Emenike E, Meleger AL. Neuropathic low back pain. Curr Pain
Headache Rep 2005; 9:168-177.

5. Freynhagen R, Baron R. The evaluation of neuropathic components in low back pain. Curr Pain Headache Rep 2009; 13:185-190.

6. Cohen SP, Mao J. Neuropathic pain: Mechanisms and their clinical implications. BMJ 2014; 348:f7656.

7. Leo RJ, Latif T. Repetitive transcranial magnetic stimulation (rTMS) in experimentally induced and chronic neuropathic pain: A review. J Pain 2007; 8:453-459.

8. Lefaucheur JP. Cortical neurostimulation for neuropathic pain: state of the art and perspectives. Pain 2016; 157:81-89.

9. Cruccu G, Garcia-Larrea L, Hansson
$P$, et al. EAN guidelines on central neurostimulation therapy in chronic pain conditions. Eur J Neurol 2016; 23:1489-1499.

10. Price DD, McGrath PA, Rafii A, et al. The validation of visual analogue scales as ratio scale measures for chronic and experimental pain. Pain 1983; 17:45-56.

11. Fairbank, JC, Pynsent PB. The Oswestry Disability Index. Spine 2000; 25:2940-2953.

12. Yakut $E$, Düger $T$, Öksüz Ç, et al. Validation of the Turkish version of the Oswestry Disability Index for patients with low back pain. Spine 2004; 29:581-585.

13. Bouhassira D, Attal $\mathrm{N}$, Alchaar $\mathrm{H}$, et al. Comparison of pain syndromes 
associated with nervous or somatic lesions and development of a new neuropathic pain diagnostic questionnaire (DN4). Pain 2005; 114:29-36.

14. Unal-Cevik I, Sarioglu-Ay S, Evcik D. A comparison of the $\mathrm{DN}_{4}$ and LANSS questionnaires in the assessment of neuropathic pain: Validity and reliability of the Turkish version of $\mathrm{DN}_{4}$. J Pain 2010; 11:1129-1135.

15. Buysse DJ, Reynolds CF 3rd, Monk $\mathrm{TH}$, et al. The Pittsburgh Sleep Quality Index: A new instrument for psychiatric practice and research. Psychiatry Res 1989; 28:193-213.

16. Agargün, MY, Kara H, Anlar Ö. The validity and reliability of the Pittsburgh Sleep Quality Index. Turk Psikiyatri Derg 1996; 7:107-115.

17. Beck AT, Steer RA, Brown GK. Beck depression inventory-II. San Antonio, Psychological Corporation 1996; 78:490-498.

18. Kapci EG, Uslu R, Turkcapar H, Karaoglan A. Beck Depression Inventory II: Evaluation of the psychometric properties and cut-off points in a Turkish adult population. Depress Anxiety 2008; 25:E104-E110.

19. Goubert D, Danneels L, GravenNielsen T, Descheemaeker F, Coppieters I, Meeus M. Differences in pain processing between patients with chronic low back pain, recurrent low back pain and fibromyalgia. Pain Physician 2017; 20:307-318.

20. Shipton E. Post-surgical neuropathic pain. ANZJ Surg 2008; 78:548-555.

21. La Moraleja US, Avellanal M. Transforaminal epiduroscopy in patients with failed back surgery syndrome. Pain Physician 2019; 22:89-95.

22. Kumar K, Taylor RS, Jacques L, et al. Spinal cord stimulation versus conventional medical management for neuropathic pain: A multicentre randomised controlled trial in patients with failed back surgery syndrome. Pain 2007; 132:179-188.

23. Rasche D, Rinaldi, PC, Young RF, et al. Deep brain stimulation for the treatment of various chronic pain syndromes. Neurosurg Focus 2006; 21:1-8.

24. Stadler JA III, Ellens DJ, Rosenow JM. Deep brain stimulation and motor cortical stimulation for neuropathic pain. Curr Pain Headache Rep 2011; 15:8-13.

25. Johnson S, Summers J, Pridmore S. Changes to somatosensory detection and pain thresholds following high frequency repetitive TMS of the motor cortex in individuals suffering from chronic pain. Pain 2006; 123:187-192.

26. Pei Q, Wu B, Tang Y, et al. Repetitive transcranial magnetic stimulation at different frequencies for postherpetic neuralgia: A double-blind, shamcontrolled, randomized trial. Pain Physician 2019; 22:E303-E313.

27. Lefaucheur JP, Drouot X, Nguyen JP. Interventional neurophysiology for pain control: Duration of pain relief following repetitive transcranial magnetic stimulation of the motor cortex. Neurophysiol Clin 2001; 31:247-252.

28. Lefaucheur JP, Drouot X, MenardLefaucheur I, et al. Neurogenic pain relief by repetitive transcranial magnetic cortical stimulation depends on the origin and the site of pain. J Neurol Neurosurg Psychiatry 2004; 75:612-616.

29. Andrade CD, Mhalla A, Adam F, et al. Neuropharmacological basis of rTMS-induced analgesia: The role of endogenous opioids. Pain 2011; 152:320-326.

30. Denis N, Nguyen JP, de Chauvigny E, et al. Value of repetitive transcranial magnetic stimulation of the motor cortex in the management of refractory cancer pain in palliative care: A case report. J Palliative Care Med 2013; 3:2.

31. Kedzior KK, Reitz SK. Short-term efficacy of repetitive transcranial magnetic stimulation (rTMS) in depressionreanalysis of data from meta-analyses up to 2010. BMC Psychol 2014; 2:39.

32. Hosomi K, Saitoh $Y$, Kishima $H$, et al. Repetitive transcranial magnetic stimulation for neuropathic pain. Funct Neurosurg 2008; 47:135-140.

33. Saitoh Y, Hirayama A, Kishima H, et al. Stimulation of primary motor cortex for intractable deafferentation pain. Acta Neurochir Suppl 2006; 99:57-59.

34. Velasco F, Carrillo-Ruiz JD, Castro G, et al. Motor cortex electrical stimulation applied to patients with complex regional pain syndrome. Pain 2009; 147:91-99. 